\title{
Reinstatement of extinguished fear by an unextinguished conditional stimulus
}

\author{
Lindsay R. Halladay ${ }^{1}{ }^{*}$, Moriel Zelikowsky ${ }^{1}$, Hugh T. Blair ${ }^{1}$ and Michael S. Fanselow ${ }^{1,2}$ \\ ${ }^{1}$ Department of Psychology, University of California at Los Angeles, Los Angeles, CA, USA \\ ${ }^{2}$ Department of Psychiatry and Biobehavioral Sciences, University of California at Los Angeles, Los Angeles, CA, USA
}

Edited by:

Martine Ammassari-Teule, Consiglio

Nazionale delle Ricerche, Italy

Reviewed by:

Pascale Gisquet-Verrier

Université Paris-Sud, France

Leonardo Restivo, Hospital for Sick

Children, Canada

\section{${ }^{*}$ Correspondence:}

Lindsay R. Halladay, Department of Psychology, University of California at Los Angeles, 1285 Franz Hall, Los Angeles, CA 90095-1563, USA. e-mail: Irhalladay@ucla.edu

\begin{abstract}
Anxiety disorders are often treated using extinction-based exposure therapy, but relapse is common and can occur as a result of reinstatement, whereby an aversive "trigger" can reinstate extinguished fear. Animal models of reinstatement commonly utilize a Pavlovian fear conditioning procedure, in which subjects are first trained to fear a conditional stimulus (CS) by pairing it with an aversive unconditional stimulus (US), and then extinguished by repeated presentations of the CS alone. Reinstatement is typically induced by exposing subjects to an aversive US after extinction, but here we show that exposure to a non-extinguished CS can reinstate conditional fear responding to an extinguished CS, a phenomenon we refer to as "conditional reinstatement" (CRI). Rats were trained to fear two CSs (light and tone) and subsequently underwent extinction training to only one CS (counterbalanced). Presenting the unextinguished CS (but not a novel cue) immediately after extinction reinstated conditional fear responding to the extinguished CS in a test session given $24 \mathrm{~h}$ later. These findings indicate that reinstatement of extinguished fear can be triggered by exposure to conditional as well as unconditional aversive stimuli, and this may help to explain why relapse is common following clinical extinction therapy in humans. Further study of CRI using animal models may prove useful for developing refined extinction therapies that are more resistant to reinstatement.
\end{abstract}

Keywords: reinstatement, fear extinction, fear conditioning

\section{INTRODUCTION}

In Pavlovian fear conditioning, subjects are trained to fear a previously neutral conditional stimulus (CS) by pairing it with an aversive unconditional stimulus (US) until the CS comes to evoke "emotional" fear responses, which in rodents are commonly measured by species-specific defense reactions such as freezing (Fanselow, 1980; Sigmundi et al., 1980). Extinction of conditional fear occurs when the previously conditioned CS is repeatedly presented without the US, causing fear responding to diminish (Pavlov, 1927; Rescorla and Heth, 1975; Bouton and Bolles, 1979). In humans, the phenomenon of fear extinction is exploited by clinical therapies for anxiety disorders, in which patients learn to reduce responses to fear-arousing stimuli by repeated unreinforced exposures (Marks, 1979; de Silva and Rachman, 1983; Mineka, 1985; Davey, 1997; Bouton et al., 2001; Eelen and Vervliet, 2006; Craske et al., 2008).

Evidence indicates that fear extinction does not simply "erase" the previously learned CS-US association, but instead forms a new memory that the CS has become safe, which inhibits expression of the original fear memory (Pavlov, 1927; Konorski, 1948; for review, see Lattal et al., 2006; but see also Kim et al., 2007). Supporting this, it is well established that after extinction, conditional fear responses to a CS can re-emerge without any additional CS-US pairings by the mere passage of time (spontaneous recovery; Pavlov, 1927; Robbins, 1990), by presenting the extinguished CS in a context other than the extinction context (renewal; Bouton and Bolles, 1979; Bouton and King, 1983), or by non-contingent presentations of the US (reinstatement; Rescorla and Heth, 1975; Bouton and Bolles, 1979). Hence, fear extinction is a rather fragile phenomenon, and this may limit the effectiveness of extinction-based therapies for anxiety disorders (Boschen et al., 2009).

Reinstatement of fear responding has been demonstrated both in animal (Rescorla and Heth, 1975; Bouton and Bolles, 1979; Kim and Richardson, 2007) and human studies (Hermans et al., 2005; Dirikx et al., 2007). Reinstatement is typically induced by re-exposure to an aversive unconditional stimulus, but here we investigated whether exposure to a non-extinguished conditional stimulus would have the capability to reinstate conditional fear responding to an extinguished CS. Rats were trained to fear two different CSs, a light and tone, by pairing them with a footshock US. One of the CSs was then extinguished by repeatedly presenting it without the US. The unextinguished CS was then presented shortly after extinction, and it was found that this reinstated conditional fear to the extinguished CS, in much the same way that prior studies have shown reinstatement by an aversive US. Based upon these findings, we argue that standard reinstatement of fear by a US might more accurately be referred to as "unconditional reinstatement," whereas reinstatement of fear by a CS (as shown here) can be referred to as "conditional reinstatement" (CRI). Mechanisms which may underlie this CRI phenomenon, as well as implications for the effectiveness of extinction therapy in human anxiety disorders, are discussed. 


\section{MATERIALS AND METHODS SUBJECTS}

Adult male Long-Evans rats ( $n=32$; Harlan, Indianapolis, IN, USA) weighing 270-300 g were housed singly and maintained on a 12-h light/dark cycle with access to food and water ad libitum. Prior to behavioral training, rats were handled daily ( 2 min per rat) for 7 days. All experimental procedures were approved by the UCLA Animal Research Committee and were conducted in accordance with USA federal guidelines.

\section{APPARATUS}

All experimental equipment and software was manufactured by Med Associates, Inc. (St. Albans, VT, USA). Behavioral experiments were carried out in acoustically isolated fear conditioning chambers $(30 \mathrm{~cm} \times 25 \mathrm{~cm} \times 25 \mathrm{~cm})$ with floors composed of stainless steel rods wired to a shock generator and scrambler operated by a programmable stimulus controller. Fear was indexed by defensive freezing, which was scored using the automated near infrared (NIR) video tracking program VideoFreeze ${ }^{\mathrm{TM}}$, which recorded behavior at 30 frames/s. Rats were considered to be freezing during episodes when the video image activity fell below a calibrated threshold during 30 or more continuous frames (Jacobs et al., 2010). Rats received fear conditioning sessions in one room (henceforth designated as Context A) and fear extinction and testing sessions in another room (henceforth, Context B). The experimental room corresponding to Contexts A vs $B$ was counterbalanced across rats in each experimental group.

One context included chambers with white plastic inserts curving inward from the back of the chamber and a grid floor with stainless steel rods ( $4.8 \mathrm{~mm}$ thick) spaced $1.6 \mathrm{~cm}$ apart (center to center). Underlying pans were scented with 50\% Simple Green and cleaned with $70 \%$ isopropyl alcohol. Chambers were illuminated with white house lights. Fans mounted above each chamber provided background noise $(60 \mathrm{~dB})$. Rats were transported to the context in their home cages, hung on racks mounted to a portable cart and covered with a white sheet.

The alternative context included chambers with aluminum side walls, an opaque plastic rear wall, and a distinct grid floor pattern consisting of two planes of "staggered" stainless steel rods $(4.8 \mathrm{~mm}$ thick) spaced $1.6 \mathrm{~cm}$ apart. Chambers were scented and cleaned with a $1 \%$ acetic acid solution. Chamber house lights and background fans were turned off. Rats were transported to the context in their home cages, placed adjacent to each other on a portable cart and covered with a metal grate.

\section{ACQUISITION AND EXTINCTION TRAINING}

All rats were delay conditioned in Context A to fear two different CSs: a $30 \mathrm{~s}$ tone $(80 \mathrm{db}, 2800 \mathrm{~Hz})$ and house light flashing at $1 \mathrm{~Hz}$ $(0.5 \mathrm{~s}$ on/ $/ 0.5 \mathrm{~s}$ off $)$ for $30 \mathrm{~s}$. Rats were not pre-exposed to Context A prior to training. Over 2 days of training, rats were given eight CS-US pairings per day (four alternating presentations of each CS, with order of presentation counterbalanced across groups) for a total of 16 CS-US pairings (eight per CS). During paired trials, each 30 s CS co-terminated with a 2 -s footshock $(1.0 \mathrm{~mA})$, with a constant intertrial interval (ITI) of $4 \mathrm{~min}$ (and a $3 \mathrm{~min}$ baseline period preceding the first pairing trial of each training session). Twenty-four hours after the second training session, rats were pre-exposed to Context B for $38 \mathrm{~min}$ (approximately the length of an extinction session) to extinguish any contextual fear that might have generalized from Context A to Context B. The following day, rats began extinction training on one of the CSs (light or tone, counterbalanced across and within context assignments), henceforth designated as $\mathrm{CS}_{\mathrm{Ext}}$. Two extinction sessions were given on two consecutive days, each beginning with a 3min baseline period, followed by 30 presentations of $\mathrm{CS}_{\mathrm{Ext}}(30 \mathrm{~s}$ each, with a 1-min ITI). In total, rats received 60 extinction trials over 2 days.

\section{REINSTATEMENT AND EXTINCTION TESTING}

After the final presentation of $\mathrm{CS}_{\mathrm{Ext}}$ on Extinction Day 2, rats remained in Context $\mathrm{B}$ for an additional $4 \mathrm{~min}$, and then received differing treatments in each group (Figure 1). The CRI group received eight unpaired "reminder" presentations of the unextinguished CS $\left(\mathrm{CS}_{\text {Unext }}\right)$ separated by a $1 \mathrm{~min}$ ITI, the novel (NOV) group received eight unpaired presentations of a novel cue $\left(\mathrm{CS}_{\mathrm{Nov}}\right.$; $73 \mathrm{~dB}$ white noise for $30 \mathrm{~s}$ ), and the control (CTRL) and unextinguished (UNEXT) groups did not receive any additional stimulus, but remained in Context $\mathrm{B}$ for an equal amount of time as the other two groups. Rats were returned to Context B $24 \mathrm{~h}$ following Extinction Day 2 for testing of their fear responses to the extinguished $\mathrm{CS}_{\mathrm{Ext}}$ (CTRL, NOV, CRI groups) or unextinguished $\mathrm{CS}_{\text {Unext }}$ (UNEXT group). The test session began with a 3-min baseline period followed by eight CS presentations (lasting $30 \mathrm{~s}$ each with a $1 \mathrm{~min}$ ITI).

\section{RESULTS}

All rats ( $n=8$ per group; 32 total) were conditioned to fear the light and tone CS during 2 days of acquisition training in Context A (Figure 2). CS-evoked freezing was averaged across all trials on Acquisition Day 2, and analyzed using a $2 \times 4$ repeated measures ANOVA with CS ( $\mathrm{CS}_{\text {Ext }}$ vs $\left.\mathrm{CS}_{\text {Unext }}\right)$ as a within-subject factor and group (CTRL vs UNEXT vs CRI vs NOV) as a between-subject factor. Freezing did not differ with group $\left(F_{3,21}<1, p=0.81\right)$ or CS type $\left(F_{1,7}<1, p=0.95\right)$, indicating that all rats acquired similar CS-evoked fear responses to both CSs. After acquisition, rats were given a day of pre-exposure to Context $\mathrm{B}$, and then underwent extinction training to $\mathrm{CS}_{\mathrm{Ext}}$ (light or tone, counterbalanced) by delivering 30 unpaired presentations of $\mathrm{CS}_{\mathrm{Ext}}$ per day for 2 days (see "Apparatus," and "Acquisition and Extinction Training").

Figure 3 shows freezing responses during extinction and test sessions. Baseline freezing to Context B was analyzed by conducting a series of one-way ANOVAs (one for each day) with treatment group (CTRL vs UNEXT vs CRI vs NOV) as the independent factor. There were no group differences in baseline freezing on Extinction Day $1\left(F_{3,28}=0.34, p=0.793\right.$; Figure 3A), Extinction Day $2\left(F_{3,28}=0.09, p=0.968\right.$; Figure $\left.3 \mathrm{~B}\right)$, or Test Day $\left(F_{3,28}=1.41, p=0.260\right.$; Figure $\left.3 \mathrm{C}\right)$. Freezing to $\mathrm{CS}_{\mathrm{Ext}}$ on each extinction day was analyzed using a $6 \times 4$ ANOVA with extinction block (1-6) as a within-subject factor and treatment group (CTRL vs UNEXT vs CRI vs NOV) as a between-group factor. The main effect of block was highly significant on both Day $1\left(F_{5,140}=7.56\right.$, $p<0.001)$ and Day $2\left(F_{5,140}=6.57, p<0.001\right)$, indicating that, as 


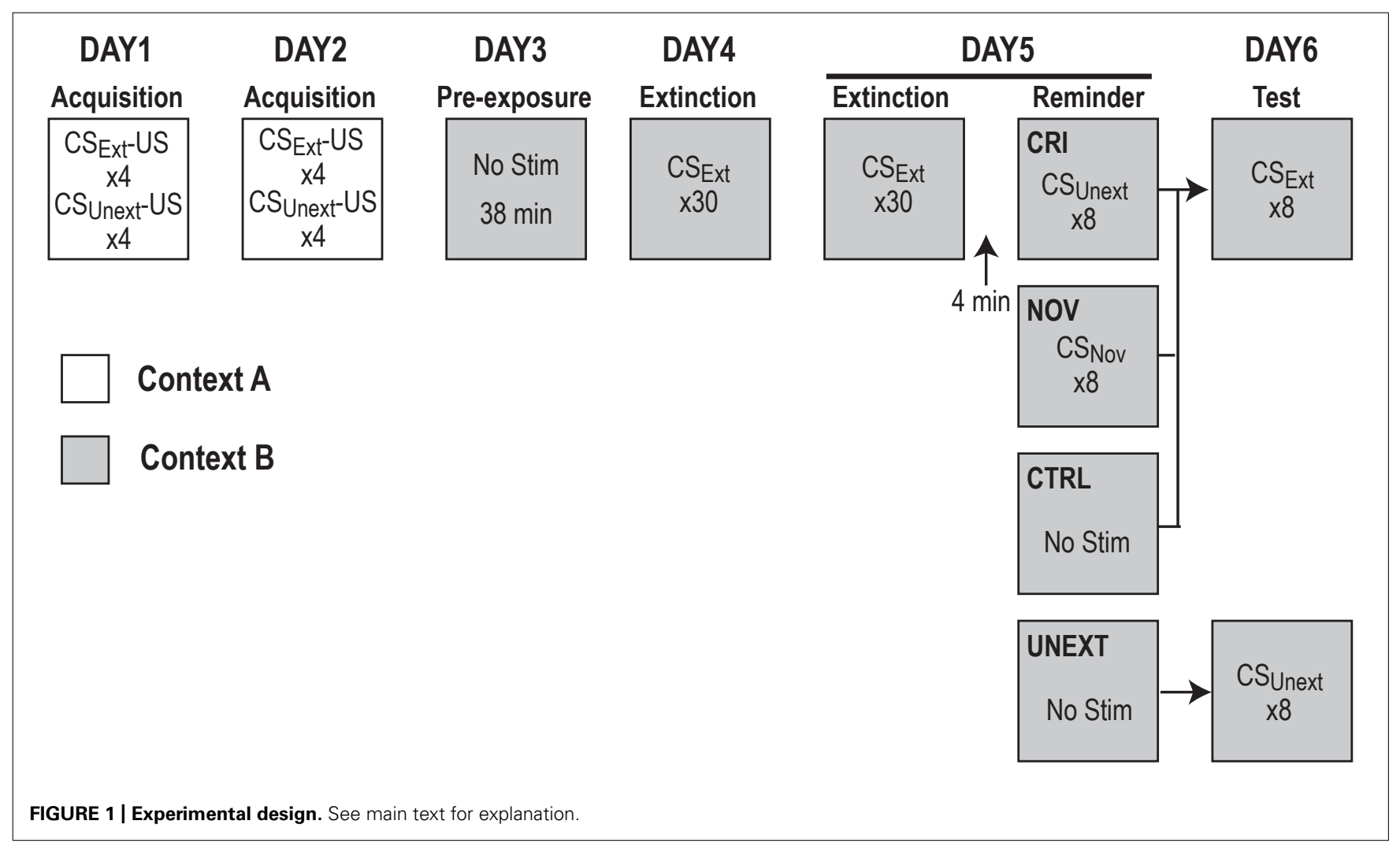

expected, freezing decreased across extinction trials. There was no main effect of group $\left(F_{3,28}=2.25, p=0.104\right)$ or block $\times$ group interaction $\left(F_{15,140}=1.3, p=0.21\right)$ on Day 2 , indicating that by the end of extinction trials, all groups had similarly extinguished their responding to $\mathrm{CS}_{\mathrm{Ext}}$.

Immediately after extinction on Day 2, rats in the CRI group received eight "reminder" trials during which $\mathrm{CS}_{\text {Unext }}$ was presented (Figure 3B, shaded area). In this group of rats, freezing to $\mathrm{CS}_{\text {Unext }}$ (averaged across all eight reminder trials) was not significantly different from freezing to $\mathrm{CS}_{\mathrm{Ext}}$ during the first trial block of Extinction Day 1 (paired $t=0.12, p=0.909$ ), indicating that the rats were still afraid of $\mathrm{CS}_{\text {Unext }}$ after responding to $\mathrm{CS}_{\text {Ext }}$ had been extinguished. Further supporting this conclusion, freezing to $\mathrm{CS}_{\text {Unext }}$ during the reminder trials was significantly greater than during the last trial block of Extinction Day 2 (paired $t=5.59, p=0.0008$ ). Hence, in the CRI group, extinction of conditional responding to $\mathrm{CS}_{\text {Ext }}$ did not generalize to $\mathrm{CS}_{\text {Unext }}$. In addition, freezing to $\mathrm{CS}_{\text {Unext }}$ during reminder trials in the CRI group was significantly greater than freezing to post-extinction presentations of $\mathrm{CS}_{\mathrm{Nov}}$ in the NOV group (independent $t=2.73$, $p=0.016)$. This provides additional evidence that freezing during the reminder trials in the CRI group was indeed a Pavlovian fear response to $\mathrm{CS}_{\text {Unext }}$, rather than an unlearned response to the unexpected presentation of a stimulus other than $\mathrm{CS}_{\mathrm{Ext}}$ at the end of extinction training.

Conditional stimulus-evoked freezing during the test session (see Figure 3C) was analyzed using a one-way ANOVA with group (CTRL vs UNEXT vs CRI vs NOV) as an independent factor. There was a significant main effect of group $\left(F_{3,28}=3.72, p=0.023\right)$.
Planned comparisons revealed that freezing to $\mathrm{CS}_{\mathrm{Ext}}$ was significantly greater in CRI rats than in CTRL $(p=0.021)$ or NOV $(p=0.016)$ rats, but not different from freezing in UNEXT rats $(p=0.770)$. However, freezing to $\mathrm{CS}_{\mathrm{Ext}}$ in NOV rats was no different than in CTRL rats $(p=0.913)$, so reinstatement of fear responding was only triggered by presentations of an unextinguished CS, and not a novel stimulus, during the reminder period following the last trial block of extinction on Day 2. These results indicate that presentations of $\mathrm{CS}_{\text {Unext }}$ triggered reinstatement of conditional fear responding to $\mathrm{CS}_{\mathrm{Ext}}$.

\section{DISCUSSION}

Here we have shown that in rats, conditional fear responding to an extinguished CS can be reinstated by the presentation of an unextinguished CS (but not a novel stimulus). This suggests that reinstatement of fear can be triggered not only by an aversive US (as in traditional "unconditional" reinstatement), but also by conditional aversive stimuli that have previously become associated with shock. This phenomenon of CRI may have implications for clinical outcomes of extinction therapy in human anxiety disorders, because it implies that relapse might be triggered by a broader variety of stimuli than has previously been appreciated.

\section{WHEN DOES REINSTATEMENT OCCUR?}

"Reinstatement" typically refers to the ability of re-exposure to a US to cause re-emergence of conditional responding after extinction. However, conditional fear responding to a formerly contingent CS has been shown to re-emerge after encountering 


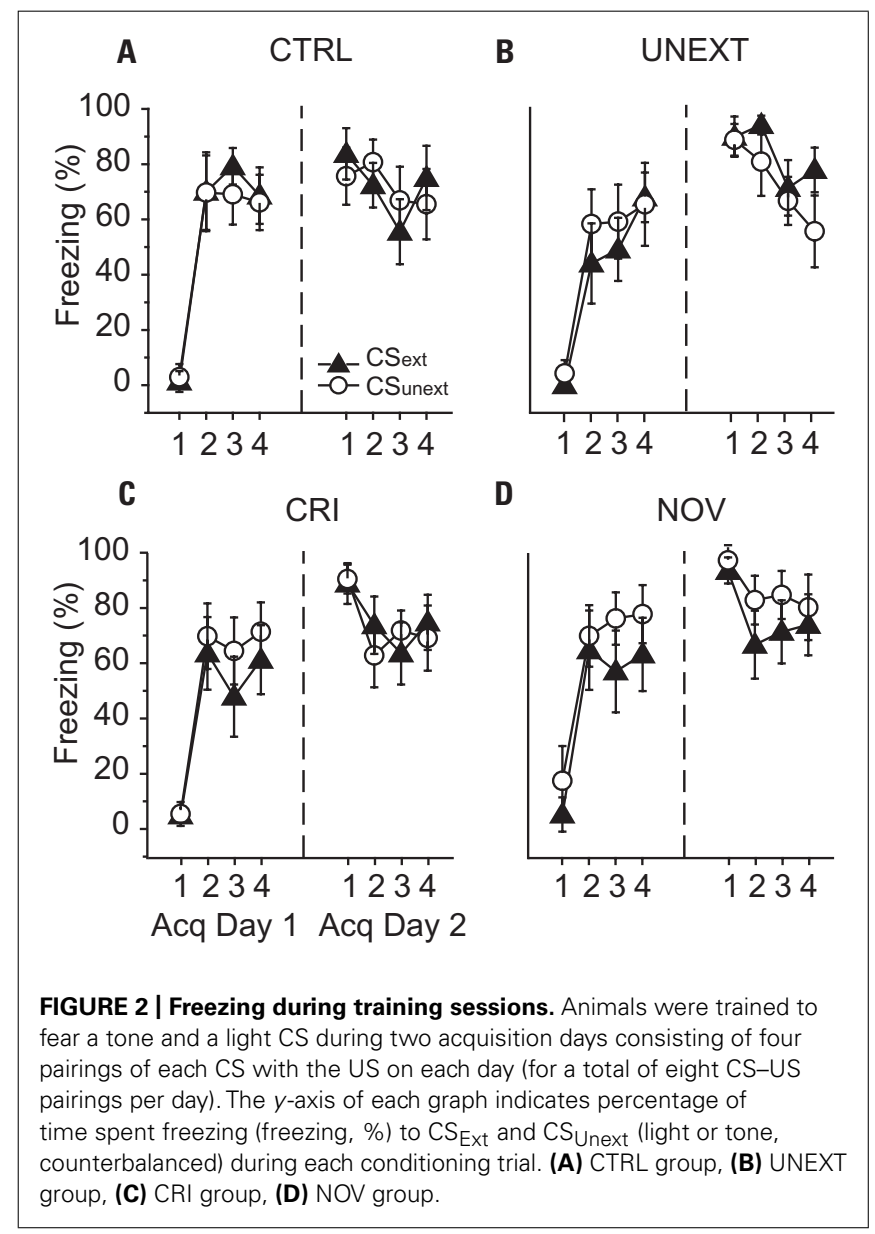

aversive stimuli relevant, but not identical, to a previously conditioned US, such as non-contingent presentations of a shock of differing intensity (Kim and Richardson, 2007), or after presentation of a qualitatively different US, like a loud noise (Rescorla and Heth, 1975). Hence, reinstatement does not seem to depend upon the specific sensory properties of the stimulus, but rather upon its ability to activate a representation of the affective properties of the aversive US (Rescorla and Heth, 1975). This idea is further supported by evidence that reinstatement can occur after biological manipulations triggering arousal, such as electrical stimulation of the amygdala (Kellett and Kokkinidis, 2004), systemic epinephrine (Haroutunian and Riccio, 1977; Morris et al., 2005b), administration of adrenocorticotropin (Richardson et al., 1984; Ahlers and Richardson, 1985), or exposure to a "dangerous" context (Morris et al., 2005a).

Results presented here are consistent with these prior findings, in that they demonstrate how an aversively valent experience (i.e., encountering an unextinguished CS) can cause the re-emergence of conditional fear to a previously extinguished stimulus. This effect was not seen in animals presented with a novel stimulus rather than the unextinguished CS, suggesting that the emotional valence associated with the unextinguished CS was essential to the reinstatement of conditional responding. The extinguished and unextinguished CS were both paired with the same US during training in our study, but an interesting question for future studies is whether fear to an extinguished CS might also be reinstated by exposure to unextinguished CS that has been previously associated with a different aversive US. If so, then this would suggest that the unextinguished CS may act as a "nonspecific stressor" to reinstate conditioned fear, perhaps in a way that is similar to how an extinguished operant drug-seeking

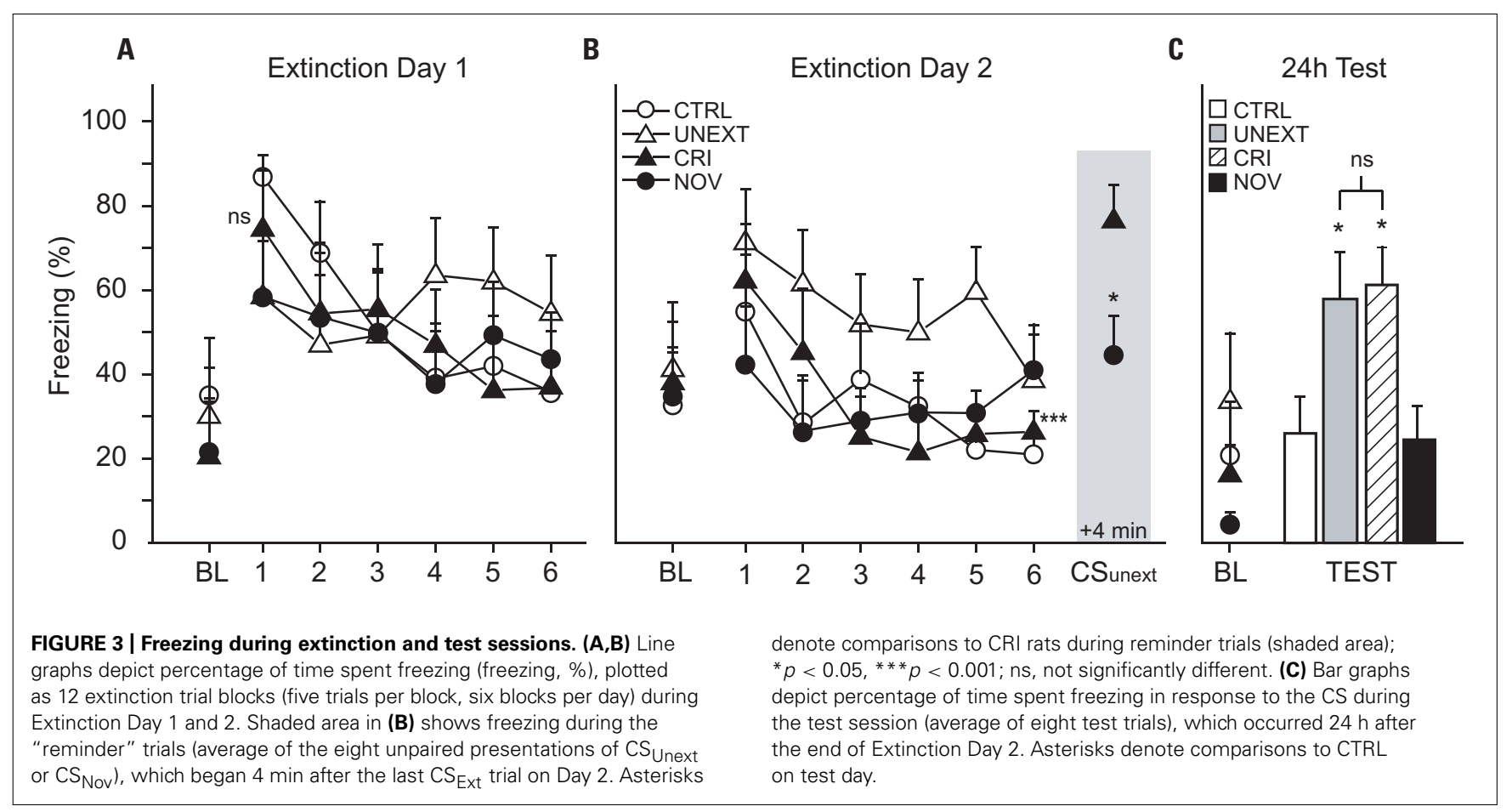


response can be reinstated by a non-specific stressor that has not previously been associated with the operant response or its rewarding outcome (Shaham and Stewart, 1994; Ahmed and Koob, 1997).

In contrast with our present findings, Rescorla and Cunningham (1978) found that non-reinforced presentations of an unextinguished light CS did not reinstate conditioned fear responses to an auditory CS that had been extinguished 5 days earlier, but instead, selectively attenuated fear responses on the first (but not the second) extinguished CS trial. The failure of the unextinguished CS to reinstate conditioned fear in this prior study may be attributable to differences between the procedures of that study vs the present study. For example, Rescorla and Cunningham (1978) trained each CS on separate acquisition days, while our study used alternating presentations of each CS on two identical acquisition days. It is thus possible that concurrent training allowed the two CSs to serve as "reminders" for one another in the present study, in contrast with the study of Rescorla and Cunningham (1978). Second, the CS $S_{\text {Unext }}$ reminder period occurred just minutes after the last extinction trial (and $24 \mathrm{~h}$ before test) in the present study, while Rescorla and Cunningham (1978) did not present the unextinguished CS until just prior to test (more than 5 days after extinction training). It has been shown that fear memory traces and conditioned behavioral responses fluctuate with time (Kamin, 1957; Glickman, 1961; McGaugh, 1966; Huppert and Deutsch, 1969; DeVietti and Hopfer, 1974; Holloway and Sturgis, 1976; Nader et al., 2000; Myers et al., 2006; Monfils et al., 2009). For example, presentations of a CS or US enhanced performance on a fear avoidance task if presented $1 \mathrm{~h}$ after training, but not after a longer delay (i.e., 3 or 21 days; Gisquet-Verrier et al., 1989). If time interacts with memory retrieval, the intervals used here between extinction, presentations of $\mathrm{CS}_{\text {Unext }}$, and testing may have been one determinant of our findings.

\section{MECHANISMS FOR EXTINCTION AND REINSTATEMENT}

Delivering unreinforced presentations of a previously trained CS in an extinction context may cause the extinction context to form two competing associations with the US. First, the extinction context may become a conditioned inhibitor of the US (Pavlov, 1927), because unreinforced presentations of the CS can trigger negative error signals that cause the extinction context to predict the absence of shock (Rescorla, 1979). Second, extinction may result in second order conditioning of the context, whereby pairing the extinction context with the trained CS makes it a second-order predictor of the US (Rizley and Rescorla, 1972). Which of these two processes dominates may depend upon the number of CS presentations given in the extinction context. It has been shown that when discrete (rather than contextual) cues are paired with non-reinforced presentations of a previously trained CS, small numbers of pairings tend to produce second-order conditioning, whereas large numbers of pairings tend to produce conditioned inhibition (Yin et al., 1994). Extinction requires that many non-reinforced CS presentations take place in the extinction context, and this may cause the extinction context to become a conditioned inhibitor of the US. Indeed, it has been suggested that extinction itself may result from conditioned inhibition, whereby the extinction context forms an inhibitory association with the US that sums with the excitatory association between the CS and US, thereby canceling out conditioned responding (Rescorla and Cunningham, 1977; Rescorla, 1979).

A "pure" conditioned inhibitor should be able to inhibit any predictor of the US, so if the extinction context becomes a conditioned inhibitor, it follows that conditioned responding to any CS (not just the extinguished CS) should become attenuated in the extinction context. Supporting this prediction, some prior studies have yielded evidence for generalization of extinction across CSs (Pavlov, 1927; Dubin and Levis, 1974). However, other studies have reported that responding diminishes selectively to the extinguished CS and not other CSs (Bouton and King, 1983; Holland and Lamare, 1984; Richards and Sargent, 1984). In our present study, rats in the CRI group showed robust freezing to the unextinguished $\mathrm{CS}_{\text {Unext }}$ when it was presented in the same extinction context where unpaired presentations of $\mathrm{CS}_{\text {Ext }}$ had been delivered, so we did not observe evidence for generalization of extinction across CSs as would be expected if the extinction context had become a conditioned inhibitor.

As an alternative to conditioned inhibition account of extinction, it has been proposed that unreinforced CS presentations may cause the extinction context to become a "negative occasion setter" that gates conditional responding to the CS (Bouton, 1993, 1994; Brooks and Bouton, 1993; Schmajuk and Holland, 1998). In contrast to a conditioned inhibitor, an occasion setter modulates the ability of a specific CS to predict the US, rather than forming a direct inhibitory association with the US itself (Holland and Lamare, 1984; Holland, 1989). Under this view of extinction, reinstatement could be explained by assuming that encountering an aversive US in the extinction context alters the representation of the context in a way that prevents it from continuing to act as a negative occasion setter for the extinguished CS (Bouton and Swartzentruber, 1986). It has been reported that the spatial firing properties of hippocampal place cells in a context are altered after presentations of a shock in that context (Moita et al., 2003), and this could provide a mechanism by which reinstatement shocks could alter the neural representation of a context that has become a negative occasion setter. If so, then our present findings suggest that if negative occasion setting does occur during fear extinction, then the context representation may be altered not only by US presentations (as during standard unconditional reinstatement), but by presentations of an unextinguished CS as well (as in the CRI observed here).

Reinstatement of fear conditioning may occur because presenting the US (or another aversive stimulus) in the extinction context results in contextual fear conditioning (Bouton and Bolles, 1979), which subsequently counteracts the ability of the extinction context to inhibit conditional responding (and may even endow the context with an ability to excite conditioned responding). If reinstatement after extinction results from contextual fear conditioning, then reinstatement might be expected to cause an increase in baseline freezing to the extinction context after reinstatement. By extension, CRI might result from second-order conditioning of the context by pairing it with the unextinguished CS 
(note that the unextinguished CS is only presented a few times in the extinction context, and this may favor second-order conditioning over conditioned inhibition). But in our study, rats in the CRI group showed no elevation of baseline freezing to the context during the test session, and thus it does not appear that second-order context conditioning accounted for CRI.

Alternatively, the unextinguished CS may reinstate responding to the extinguished CS by acting as a reminder of the acquisition context and thereby facilitating retrieval of the CS-US association over the CS-noUS association (Bouton, 1993; Brooks and Bouton, 1993). Recently, Winterbauer and Bouton (2010) reported that an extinguished lever-press response would "resurge" if a second unextinguished lever was presented. In this case, the unextinguished lever could have acted much as our unextinguished CS. However, in these experiments the reminder cue was administered during the test of the extinguished response. The reinstatement we observed occurred when the putative reminder cue was presented $24 \mathrm{~h}$ prior to test as part of the extinction session. Thus, presentation of an unextinguished cue appears to have both immediate and long-term consequences for a response that was previously extinguished.

If the unextinguished CS acted as a reminder cue, then the extinguished CS-US association might somehow have been recalled and reconsolidated after presentation of the unextinguished reminder cue. However, this would have required the unextinguished CS to trigger reconsolidation of the extinguished CS's association with the US. Prior results indicate that reconsolidation of one CS can be disrupted without affecting reconsolidation of another CS (Debiec et al., 2006), so it does not seem that reconsolidation generalizes easily between cues. Hence, it seems unlikely that the unextinguished CS triggered reconsolidation of the extinguished CS-US association.

\section{REFERENCES}

Ahlers, S. T., and Richardson, R. (1985). Administration of dexamethasone prior to training blocks ACTH-induced recovery of an extinguished avoidance response. Behav. Neurosci. 99, 760-764.

Ahmed, S. H., and Koob, G. F. (1997). Cocaine- but not foodseeking behavior is reinstated by stress after extinction. Psychopharmacology (Berl.) 132, 289-295.

Boschen, M. J., Neumann, D. L., and Waters, A. M. (2009). Relapse of successfully treated anxiety and fear: theoretical issues and recommendations for clinical practice. Aust. N. Z. J. Psychiatry 43, 89-100.

Bouton, M. E. (1993). Context, time, and memory retrieval in the interference paradigms of Pavlovian learning. Psychol. Bull. 114, 80-99.

Bouton, M. E. (1994). Context, ambiguity, and classical conditioning. Curr. Dir. Psychol. Sci. 3, 49-53.

Bouton, M. E., and Bolles, R. C. (1979). Contextual control of the extinction of conditioned fear. Learn. Motiv. 10, 445-466.
Bouton, M. E., and King, D. A. (1983). Contextual control of the extinction of conditioned fear: tests for the associative value of the context. J. Exp. Psychol. Anim. Behav. Process. 9, 248-265.

Bouton, M. E., Mineka, S., and Barlow, D. H. (2001). A modern learning theory perspective on the etiology of panic disorder. Psychol. Rev. 108 , 4-32.

Bouton, M. E., and Swartzentruber, D. (1986). Analysis of the associative and occasion-setting properties of contexts participating in a Pavlovian discrimination. J. Exp. Psychol. Anim. Behav. Process. 12, 333-350.

Brooks, D. C., and Bouton, M. E. (1993). A retrieval cue for extinction attenuates spontaneous recovery. J. Exp. Psychol. Anim. Behav. Process. 19, 77-89.

Craske, M. G., Kircanski, K., Zelikowsky, M., Mystkowski, J., Chowdhury, N., and Baker, A. (2008). Optimizing inhibitory learning during exposure therapy. Behav. Res. Ther. 46, 5-27.

Crowson, J. J., Frueh, B. C., Beidel, D. C., and Turner, S. M.

\section{CLINICAL IMPLICATIONS}

Often, treatments for anxiety disorders such as specific phobias or PTSD rely upon fear extinction strategies to desensitize fearful stimuli (Mineka, 1985; Davey, 1997; Bouton et al., 2001; Eelen and Vervliet, 2006). CRI of fear by unextinguished conditional stimuli could be one factor that limits the effectiveness of such exposure therapy. For example, a veteran suffering from PTSD may experience anxiety and panic when encountering cues associated with the trauma from combat. Experiences such as being in large crowds or rounding blind corners may remind the veteran of combat situations, triggering PTSD symptoms (Crowson et al., 1998). If the veteran successfully undergoes exposure therapy to extinguish fear responses to these cues, but then later is exposed to untreated trauma-associated cues like hearing the sound of a helicopter (Scurfield et al., 1992), seeing or reading war-related media (Hilton, 1997), or learning about the enlistment of a family member (Nachshoni and Singer, 2006), then it is possible that the conditioned anxiety triggered by these untreated cues may conditionally reinstate memories of the associated trauma (which the "treated" CS had also been associated with), thus resulting in the re-emergence of anxiety during future encounters with the treated cues of large crowds or blind corners (effectively "undoing" the exposure therapy by CRI). A better understanding of the mechanisms underlying this CRI phenomenon may prove useful for developing extinction therapies for anxiety disorders that are more resistant against relapse by reinstatement,

\section{ACKNOWLEDGMENTS}

This work was supported by NIH Grant 5 T32 NS058280-03 awarded to Lindsay R. Halladay and NIMH RO1 MH62122 awarded to Michael S. Fanselow. We thank Martina Hlavacek for technical assistance.

(1998). Self-reported symptoms of social anxiety in a sample of combat veterans with posttraumatic stress disorder. J. Anxiety Disord. 12, 605-612.

Davey, G. C. L. (1997). "A conditioning model of phobias," in Phobias: A Handbook of Theory, Research, and Assessment, ed. G. C. L. Davey (Chichester: Wiley), 301-322.

Debiec, J., Doyere, V., Nader, K., and LeDoux, J. E. (2006). Directly reactivated, but not indirectly reactivated, memories undergo reconsolidation in the amygdala. Proc. Natl. Acad. Sci. U.S.A. 103, 3428-3433.

de Silva, P., and Rachman, S. (1983). Exposure and fear-reduction. Behav. Res. Ther. 21, 151-152.

DeVietti, T. L., and Hopfer, T. M. (1974). Complete amnesia induced by ECS and complete recovery of memory following reinstatement treatment. Physiol. Behav. 12, 599-603.

Dirikx, T., Hermans, D., Vansteenwegen, D., Baeyens, F., and Eelen, P. (2007). Reinstatement of conditioned responses in human differential fear conditioning. J.
Behav. Ther. Exp. Psychiatry 38 237-251.

Dubin, W. J., and Levis, D. J. (1974). Generalization of extinction gradients: a systematic analysis. J. Exp. Psychol. 100, 403-412.

Eelen, P., and Vervliet, B. (2006). "Fear conditioning and clinical implications: what we can learn from the past?" in Fear and Learning: From Basic Processes to Clinical Implications, eds M. G. Craske, D. Hermans, and D. Vansteenwegen (Washington, DC: American Psychological Association), 197-215.

Fanselow, M. S. (1980). Conditional and unconditional components of postshock freezing. Integr. Psychol. Behav. Sci. 15, 177-182.

Gisquet-Verrier, P., Dekeyne, A., and Alexinsky, T. (1989). Differential effects of several retrieval cues over time: evidence for time-dependent reorganization of memory. Anim. Learn. Behav. 17, 394-408.

Glickman, S. E. (1961). Preservative neural processes and consolidation of the memory trace. Psychol. Bull. 58, 218-233. 
Haroutunian, V., and Riccio, D. C. (1977). Effect of arousal conditions during reinstatement treatment upon learned fear in young rats. Dev. Psychobiol. 10, 25-32.

Hermans, D., Dirikx, T., Vansteenwegen, D., Baeyens, F., Van den Bergh, O., and Eelen, P. (2005). Reinstatement of fear responses in human aversive conditioning. Behav. Res. Ther. 43, 533-551.

Hilton, C. (1997). Media triggers of post-traumatic stress disorder 50 years after the second World War. Int. J. Geriatr. Psychiatry 12, 862-867.

Holland, P. C. (1989). Transfer of negative occasion setting and conditioned inhibition across conditioned and unconditioned stimuli. J. Exp. Psychol. Anim. Behav. Process. 15, 311-328.

Holland, P. C., and Lamare, J. (1984). Transfer of inhibition after serial and simultaneous feature negative discrimination training. Learn. Motiv. 15, 219-243.

Holloway, F. A., and Sturgis, R. D. (1976). Periodic decrements in retrieval of the memory of nonreinforcement as reflected in resistance to extinction. J. Exp. Psychol. Anim. Behav. Process. 2, 335-341.

Huppert, F. A., and Deutsch, J. A. (1969). Improvement on memory with time. J. Exp. Psychol. 21, 267-271.

Jacobs, N. S., Cushman, J. D., and Fanselow, M. S. (2010). The accurate measurement of fear memory in Pavlovian fear condition: Resolving the baseline issue. J. Neurosci. Meth. 190, 235-239.

Kamin, L. J. (1957). The retention of an incompletely learned avoidance response. J. Comp. Physiol. Psychol. 50, 457-460.

Kellett, J., and Kokkinidis, L. (2004). Extinction deficit and fear reinstatement after electrical stimulation of the amygdala: implications for kindling-associated fear and anxiety. Neuroscience 127, 277-287.

Kim, J., Lee, S., Park, K., Hong, I., Song, B., Son, G., Park, H., Kim, W. R., Park, E., Choe, H. K., Kim, H., Lee, C., Sun, W., Kim, K., Shin, K. S., and Choi, S. (2007). Amygdala depotentiation and fear extinction. Proc. Natl. Acad. Sci. U.S.A. 26, 20955-20960.

Kim, J. H., and Richardson, R. (2007). A developmental dissociation in reinstatement of an extinguished fear response in rats. Neurobiol. Learn. Mem. 88, 48-57.

Konorski, J. (1948). Conditioned Reflexes and Neuron Organization. Cambridge, MA: Cambridge University Press.

Lattal, K. M., Radulovic, J., and Lukowiak, K. (2006). Extinction: does it or doesn't it? The requirement of altered gene activity and new protein synthesis. Biol. Psychiatry 60, 344-351.

Marks, I. (1979). Exposure therapy for phobias and obsessive-compulsive disorders. Hosp. Pract. 14, 101108.

McGaugh, J. L. (1966). Time-dependent processes in memory storage. Science 153, 1351-1358.

Mineka, S. (1985). "Animal models of anxiety-based disorders: their usefulness and limitations," in Anxiety and the Anxiety Disorders, eds A. H. Tuma and J. D. Maser (Hove: Lawrence Erlbaum Associates Inc.), 199-244.

Moita, M. A., Rosis, S., Zhou, Y., LeDoux, J. E., and Blair, H. T. (2003). Hippocampal place cells acquire location-specific responses to the conditioned stimulus during auditory fear conditioning. Neuron 37, 485-497.

Monfils, M. H., Cowansage, K. K., Klann, E., and LeDoux, J. E. (2009). Extinction-reconsolidation boundaries: key to persistent attenuation of fear memories. Science 324, 951-955.

Morris, R. W., Furlong, T. M., and Westbrook, R. F. (2005a). Recent exposure to a dangerous context impairs extinction and reinstates lost fear reactions. J. Exp. Psychol. Anim. Behav. Process. 31, 40-55.

Morris, R. W., Westbrook, R. F., and Killcross, A. S. (2005b). Reinstatement of extinguished fear by betaadrenergic arousal elicited by a conditioned context. Behav. Neurosci. 119, 1662-1671.

Myers, K. M., Ressler, K. J., and Davis, M. (2006). Different mechanisms of fear extinction dependent on length of time since fear acquisition. Learn. Mem. 13, 216-223.

Nachshoni, T., and Singer, Y. (2006) Reactivation of combat stress after a family member's enlistment. Mil. Med. 171, 1211-1214.

Nader, K., Schafe, G. E., and LeDoux, J. E. (2000). The labile nature of consolidation theory. Nat. Rev. Neurosci. 1, 216-219.

Pavlov, I. V. (1927). Conditioned Reflexes: An Investigation of the Physiological Activity of the Cerebral Cortex. New York: Liveright (translated and edited by G. V. Anrep).

Rescorla, R. A. (1979). "Conditioned inhibition and extinction," in Mechanisms of Learning and Motivation: A Memorial Volume to Jerzy Konorski, eds A. Dickinson and R. A. Boakes (Hillsdale, NJ: Erlbaum), 83-110.

Rescorla, R. A., and Cunningham, C. L. (1977). The erasure of reinstated fear. Anim. Learn. Behav. 5, 386-394.

Rescorla, R. A., and Cunningham, C. L. (1978). Recovery of the US representation over time during extinction. Learn. Motiv. 9, 373-391.

Rescorla, R. A., and Heth, C. D. (1975). Reinstatement of fear to an extinguished conditioned stimulus. J. Exp. Psychol. Anim. Behav. Process. 1, 88-96.

Richards, R. W., and Sargent, D. M (1984). The order of presentation of conditioned stimuli during extinction. Anim. Learn. Behav. 22, 95-98.

Richardson, R., Riccio, D. C., and Devine, L. (1984). ACTH-induced recovery of extinguished avoidance responding. Prog. Psyhobiol. Physiol. Psychol. 12, 184-192.

Rizley, R. C., and Rescorla, R. A. (1972). Associations in second-order conditioning and sensory preconditioning. J. Comp. Physiol. Psychol. 81, 1-11.

Robbins, S. J. (1990). Mechanisms underlying spontaneous recovery in autoshaping. J. Exp. Psychol. Anim. Behav. Process. 16, 235-249.

Schmajuk, N. A., and Holland, P. C. (1998). Occasion Setting: Associative Learning and Cognition in Animals. Washington, DC: American Psychological Association.
Scurfield, R. M., Wong, L. E., and Zeerocah, E. B. (1992). An evaluation of the impact of "helicopter ride therapy" for in-patient Vietnam veterans with war-related PTSD. Mil. Med. 157, 67-73.

Shaham, Y., and Stewart, J. (1994). Stress reinstates heroin-seeking in drug-free animals: an effect mimicking heroin, not withdrawal. Psychopharmacology (Berl.) 119, 334-341.

Sigmundi, R. A., Bouton, M. E., and Bolles, R. C. (1980). Conditioned freezing in the rat as a function of shock intensity and CS modality. Bull. Psychon. Soc. 15, 254-256.

Winterbauer, N. E., and Bouton, M. E. (2010). Mechanisms of resurgence of an extinguished instrumental behavior. J. Exp. Psychol. Anim. Behav. Process. 36, 343-353.

Yin, H., Barnet, R. C., and Miller, R. R. (1994). Second-order conditioning and Pavlovian conditioned inhibition: operational similarities and differences. J. Exp. Psychol Anim. Behav. Process. 20, 419-428.

Conflict of Interest Statement: The authors declare that the research was conducted in the absence of any commercial or financial relationships that could be construed as a potential conflict of interest.

Received: 13 February 2012; paper pending published: 04 April 2012; accepted: 13 April 2012; published online: 04 May 2012.

Citation: Halladay LR, Zelikowsky M, Blair HT and Fanselow MS (2012) Reinstatement of extinguished fear by an unextinguished conditional stimulus. Front. Behav. Neurosci. 6:18. doi: 10.3389/fnbeh.2012.00018

Copyright () 2012 Halladay, Zelikowsky, Blair and Fanselow. This is an open-access article distributed under the terms of the Creative Commons Attribution Non Commercial License, which permits noncommercial use, distribution, and reproduction in other forums, provided the original authors and source are credited. 